\title{
The Relationship of Lexical Error and their Types to the Quality of ESL Compositions: an Empirical Study
}

\author{
María Pilar Agustín Llach \\ Universidad de la Rioja
}

Received: 30 March 2004 / Version accepted: 8 June 2004

\begin{abstract}
This study investigates the question of whether there is a systematic relationship between the percentage of lexical errors, the percentage of lexical error types and quality of composition. Quality is defined as the score of the composition. The Pearson product-moment correlation coefficient is used to test the null hypothesis of no significant relationship. The study is based on the analysis of 19 compositions of students of Business English at Universidad de La Rioja. All assumptions for the statistical test were found to be met and the correlation coefficient obtained was significant at $\mathrm{p}<.01$ $(\mathrm{r}=-.78)$. The results are discussed in terms of how meaningful the relationship and resulting predictions are, and what this may mean to planners of writing courses.
\end{abstract}

Key words: lexical errors, quality of compositions, semantic errors, correlation.

RESUMEN: En este estudio se investiga la existencia de una relación sistemática entre el porcentaje de errores léxicos, las clases de errores léxicos, y la calidad de la composición escrita. La calidad se define como la puntuación obtenida en la composición. El coeficiente de correlación de Pearson se usa en esta investigación para probar la hipótesis nula de que no hay relación significativa entre esos tres aspectos antes mencionados. El estudio se basa en el análisis de 19 composiciones de estudiantes de inglés empresarial en la Universidad de La Rioja. Se probó que efectivamente existe una correlación significativa entre errores léxicos, clases de errores léxicos y calidad de la composición para p<.01 $(\mathrm{r}=-.78)$. La discusión de los resultados se centra en determinar la relevancia de la correlación y de las predicciones subsiguientes, y lo que esto significa para los diseñadores de cursos de escritura.

Palabras clave: errores léxicos, calidad de la composición, errores semánticos, correlación.

\section{INTRODUCTION}

The relationship between language proficiency and writing skills and composition evaluation is still unclear (Engber, 1995: 139). Still greater is the ignorance as regards the extent to which lexical proficiency, and above all lexical error percentage interact with and influence the writing evaluation process. Although, in these last years (from Meara, 1984 onwards) research on vocabulary and its relationship to the writing process has become more and more important, few are the studies devoted, even just partially, to lexical errors and their impact on ESL writing tasks (see Engber, 1995 for an invaluable account of this). 
Vocabulary is the basic component of language as communication is regarded. Words are the means to express meanings and without them, grammar is just a meaningless abstract construct of rules (Dagut, 1977; Laufer, 1986, 1990a; Meara, 1996). Learners carry about dictionaries not grammars when they travel to a foreign country (Rivers in Laufer, 1990a: 293). It is of special relevance, therefore, to examine the ways in which communication is distorted, in order to take the appropriate means to remedy those distractions, and make the communication process as successful and fluent as possible. There is strong evidence to believe that lexical errors and lack of lexical knowledge have a great influence on communication, as far as they are accounted for as the most distracting and pernicious of all types of errors (Hughes and Lascaratou, 1982; Gass, 1988: 93; Ellis, 1994:63). In this case, lexical errors will distort written communication, and this will have bad consequences on the quality rating of written essays. Lexical errors are judged most severely as communication distracters because they have a negative effect on the intelligibility of the message (Dagut, 1977; Johansson, 1978; Hughes and Lascaratou, 1982; Maingay and Rundell, 1987; Ellis, 1994). Different researchers who have dealt with the evaluation of errors have found out that lexical errors are graded as very serious, above all by native speaker judges (Johansson, 1978; Burt, 1975; Tomiyana, 1980; Khalil, 1985 in Ellis, 1994: 63). They also discovered the reason why lexical errors were considered to be so problematic, namely because they distort communication. The utterance with the lexical error is less intelligible than utterances with other types of errors. Intelligibility suffers at most due to lexical errors (Hughes and Lascaratou, 1982: 179). This fact of lexical errors being rated as important communication distracters and the possible negative consequences on the assessment of the written production inspired this study.

\section{BACKGROUND TO THE STUDY}

Language learning starts up with vocabulary, words are the first linguistic items acquired by the learner (in first and second language acquisition) (Dagut, 1977; Yoshida, 1978), and no language acquisition at all can take place without the acquisition of lexis (Laufer, 1986: 69). Furthermore, lexis is basic for the development of communicative competence (Widdowson, 1995), nowadays considered the last aim of a successful second language learning (Llobera, 1995; Denyer, 1998; Briz, 2002). Several studies (Verhallen and Schoonen, 1993, 1998) have also revealed the relationship between vocabulary and success in school. This has to do with the conceptualization of learning items in all subjects and the grasping of whole meanings and nuances. It seems that a larger vocabulary in breadth ${ }^{1}$, and in depth ${ }^{2}$ is intimately and positively related with high academic achievement. Some studies have accounted for the relationship between lexical proficiency and/or vocabulary development and different areas of language skills. The positive correlation between reading and vocabulary development, in

${ }^{1}$ This refers to the number of words a learner knows. This has to do with how big is the mental lexicon of the learner.

${ }^{2}$ Depth of vocabulary knowledge alludes to how well words are known as regards their meaning(s), nuances, and syntactic behaviour. 
both directions, (Grabe and Stoller, 1997; Laufer, 1997; Denyer, 1998) and vocabulary development and writing (Muncie, 2002), and writing assessment (lexical variation, originality, frequency, density, sophistication) (Laufer and Nation, 1995; Engber, 1995; Meara et al., 2000) has been repeatedly proved. This last relation interests us most here, since the evaluation of written compositions and the appearance of lexical errors in the assessed compositions seem to be intimate issues.

Lexical errors are thought to be important composition assessment criteria and quality predictors, research has proved their influence on writing evaluation to some extent, although results are too weak to be conclusive (Engber, 1995). It is difficult to establish objective measures of writing quality and evaluation criteria. Compositions are also one of the most difficult SL tasks to assess, since subjectivity is here present at its highest. Teachers rely on their own intuition of what to mark as bad (or good) writing, lexical errors play an important part in this decision, but also more personal aspects like the agreement on the ideas exposed, the liking of the topic, or his very relationship to the learner, whether they "like" him or not can also influence the score. Different authors and teachers use different assessment rates and criteria, and there are, definitely, many of them (Crusan, 2002; Jarvis et al., 2003). Crusan (2002) found out that most American universities evaluate their students writing skills by means of indirect measures, above all multiple choice tests. Laufer and Nation (1995) also comment on how several lexical measures affect the judgements of quality in writing. This disparity of evaluation criteria, together with the fact that writing assessment has an important impact on placement decisions and final grades in composition classes do not benefit the language learner, who is left in the outmost ignorance of what to base his practice of writing skills on.

Although the relationship between lexical errors and quality of composition has been dimly proved, there is a general lack of attention to lexical errors and derived phenomena and implications (Meara, 1984). This paper intends to provide a stronger claim for the relationship between lexical errors and their types and the quality of ESL compositions. Considering Engber's results (1995), this article is devoted to the analysis of the lexical errors and their correlation to writing quality score and to the investigation of lexical error type as a writing assessment measure. In order to do this, a classification of lexical errors has been developed, which is presented below in the section about procedures.

The main importance of the research are the implications the findings would have on teachers. If the correlation between lexical error types and quality of composition is finally proved, the teacher is provided with objective criteria for evaluation and with clues about what to concentrate his teaching on, namely, on the most important, most destructive lexical error types, those that cause most problems for their frequency and for their consequences to compositions. For learners the findings are important since they know what they have to pay more attention to when writing. Second language writing courses can be developed taken these (and other such) findings into account. The purpose of this study is, therefore, to determine the extent to which lexical errors and their types are related to the quality of written compositions of ESL learners with Spanish as their mother tongue and at an intermediate level. So with this purpose in mind, I set out to investigate and to prove or reject the following research hypothesis that guided the study:

1. Percentage of lexical error significantly correlates with quality of composition as expressed in its score. 
2. Percentage of lexical error type significantly correlates with quality of composition as expressed in its score.

3. Semantic lexical error type (word choice, confusion of two lexical items, or words which have suffered relexification procedures) will prove the most destructive with the worst, severest consequences in the quality score. This may be so, because this type affects the most to the meaning level of the composition, and they require a great effort on the part of the reader in terms of comprehension.

\section{THE STUDY}

\subsection{Subjects}

The 19 essays $^{3}$ used in the study were collected from a group of students at Universidad de La Rioja (UR) in Spain. The students were taking part in a course on business English (ESP), where attention is paid to the writing of commercial letters. All students had Spanish as their mother tongue, two of them were also learning French and one of them German, all at the initial stages. All except three were students of Business Administration, one studied Mathematics, other Chemistry and the third one English. The level of the English class and of the compositions they produced is intermediate ${ }^{4}$ and the students had previously had an average of 120 hours of instruction in English. The essays were the result of a timed composition writing process of 50 minutes where the student as the manager of an important liquor company had to write a letter to the chief of the Business Administration Department at the UR offering a job as an assistant for students at UR.

Intermediate students were chosen because research (Laufer, 1995: 149; Muncie, 2002) and my intuition predicted many lexical errors, and many non (easily)-understandable lexical errors, and also because of the lack of research on them (Muncie, 2002). Laufer (1998 in Muncie, 2002) believes that students at this stage have not fossilized yet, this also contributed to the selection of the written production of intermediate students for this study. No use of dictionaries or other consulting material was allowed, since problems with vocabulary were being studied and the use of dictionaries or other material would have deleted many of these problems from the students' production.

\subsection{Procedures}

Once the data had been collected, the compositions were assessed by 2 English teachers with Spanish as their native language. They had to make a holistic assessment (overall evaluation, with the composition taken and considered as a whole), the teachers used a 6point scoring scale (see Appendix A for scoring criteria). This rating was considered to be

${ }^{3}$ I thank Soraya Moreno Espinosa for her disinterested surrender of the essays.

${ }^{4}$ Essays were assessed by Soraya Moreno Espinosa following the ESL Composition Program by Jacobs (1981). For further information on this technique and its results with the essays used here, please see Moreno Espinosa (2002). 
measure of the quality of the composition (see above for the difficulty of determining what measures reflect writing quality). This quality score was compared to the percentage of lexical errors and to the percentage of the different lexical error types. The percentage of lexical errors was calculated dividing the number of words involved in a lexical error (or the number of lexical errors) by the total number of words in the composition. The result provides us with the percentage of words that are involved in lexical errors in each composition. Similarly, the percentage of lexical error type was obtained dividing the number of lexical errors of each type by the total number of words. The result gives us the percentage of lexical error type for each essay. Lexical errors were identified, analyzed and classified into the lexical error taxonomy explained below. The correlation between both variables, that is, between the quality, and the percentage of lexical errors in general, and between the quality and each type of lexical errors (rate/frequency value) was calculated. The Pearson productmoment correlation coefficient ( $\mathrm{r}$ ) was used as the measure to establish correlation and the variables were ordered in a continuous scale. This is accounted for in the results and discussion section.

\section{A. Delimitation and Definition of Lexical Error}

When dealing with lexical errors, the problem of defining what exactly is a lexical error arises early in the study. It is, indeed, important to delimit the object of study since the very beginning. After having examined the treatment given to the term lexical error in several studies $^{5}$ (Duskova, 1969; Warren, 1982; Zimmermann, 1986, 1987; Laufer, 1990a, 1991; Lennon, 1990, 1991; Zughoul, 1991), a definition of the same, as will be used here, has been established. Thus, lexical error is the wrong use of a lexical item in a particular context by comparison with what a native speaker of similar characteristics as the L2 learner (age, educational level, professional and social status) would have produced in the same circumstances (cf. Lennon, 1991). Being the lexical item an independent meaningful unit; this includes content words (nouns, verbs [also phrasal verbs], adjectives and adverbs) (Engber, 1995; Muncie, 2002) and idioms (cf. J. Bahns, 1993: 57). A lexical error implies, therefore, a breach in the lexical norm of the language, which is normally observed by native speakers. The possibility of mistakes or slips is not considered, because the written mode allows for revision and correction of undesired forms.

\section{B. Classification of lexical errors}

A taxonomy had to be used in order to classify lexical errors into different types. The classification develops as a kind of amalgam classification, which collects aspects from different taxonomies of lexical errors (Duskova, 1969; Warren, 1982; Zimmermann, 1986, 1987; Hyltenstam, 1988; Lennon, 1990, 1991; Zughoul, 1991). Three main classificatory criteria are followed in this classification: linguistic, psycholinguistic and pedagogical (see fig. 1). The linguistics criterion refers to Corder's claim (1973: 133) that "a 'word' has semantic, syntactic and phonological [orthographic] properties", to these the pragmatic properties are added, following the traditional division of linguistics in these four areas. Corder goes on

\footnotetext{
${ }^{5}$ Agustín Llach, in evaluation process.
} 
"errors of usage [lexical errors] may be at any or all of these levels." These claims serve to justify our classification from the linguistic point of view. The psycholinguistic classification criterion alludes to the cause of the lexical error from the point of view of interference from the mother tongue or from the very L2. This has to do with the learning and communication strategies, their nature (transfer, overgeneralization, simplification; cf. Richards, 1971; Taylor, 1975; Blum and Levenston, 1978) and application (sometimes wrong application) (Jiménez Catalán, 1992). Lexical errors are also classified attending to pedagogical implications. This idea is based on Laufer's finding (Laufer, 1990b) that some words are more difficult to learn than others due to some intralexical features (see also Bahns, 1993), thus lexical errors are classified depending on what content word or idiom is affected by the error ${ }^{6}$.

The scope of this study does not allow us to implement a thorough analysis of the correlation between the quality of composition and the different types of lexical errors depending on their source (L1, or L2), and on the class of word affected by the error. Therefore, the study confines itself to the consideration of the four types of lexical error, depending on the linguistic level at which the lexical error occurs. It would be very interesting, and I believe, also very useful for the English second language teacher to know what causes more destructive lexical errors, the mother tongue or the very target language (English). If the relationship between class of word affected by the error and quality of composition is stated, difficulty word lists could be designed that could be helpful for the teacher as an evaluation resource and guideline, and for the student as a learning device. Unfortunately, this goes beyond the scope of the study and it must limit itself to the semantic, syntactic, orthographic and pragmatic lexical error types.

Figure 1 Taxonomy of lexical errors
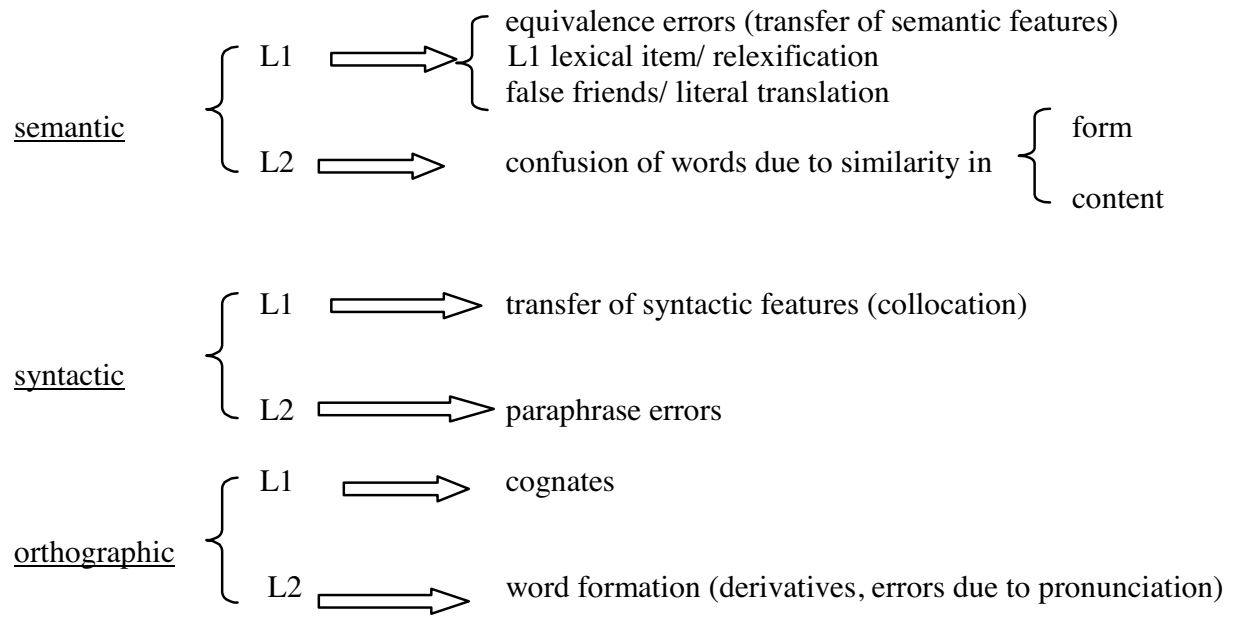

pragmatic $\Rightarrow$ style errors (L1)

${ }^{6}$ For further details on this classification see Agustín Llach Interlingüística no. 15, in print. 


\subsection{Results and discussion}

The percentage of lexical errors was correlated to the scores obtained by the compositions (see Appendix B). The mean of the scores of the two judges was used. The results of the study revealed moderate, significant correlations between percentage of lexical error (see Appendix B for percentage of lexical errors and of lexical error type) and quality score $(\mathrm{r}=-.78, \mathrm{p}<.01)$, supporting, thus, Engber's findings (1995). The null hypothesis that there is no correlation between the frequency of lexical errors and the quality of the essays can be discarded, and the alternative hypothesis is proved, fulfilling, thus, the expectation that as score increased, percentage of lexical error decreased. As has been explained before, in this study, a rather broad definition of lexical error has been used. The lexical errors considered were all those where some deviance of the native norm of English could be observed to appear affecting some lexical item, this includes errors in spelling, in choice of the lexical item, in the particles accompanying verbs, in associations of two words (collocation), and in style.

Difficulty of determining what constitutes a lexical error has been found. Sometimes, they overlapped with grammatical errors, some other times the real intention of the student was not clear, and it was not easy to decide whether the word used was "correct" or not, since word choice is a highly subjective activity. However, the context and topic of the essay were very clear, and the lexical fields and individual words that could appear in the compositions were very much restricted. This made the classification tasks much easier, and, in general, the expected lexical items, and errors affecting them turned out.

The classification of what were identified as lexical errors into the different types also proved very complex. The only types considered, as discussed previously, were the semantic, syntactic, orthographic and pragmatic lexical errors. In terms of the semantic lexical error types, the results of the study revealed a very low, significant correlation of $r=-.55(p<.01)$. This shows evidence to prove the initial hypothesis that the more semantic lexical errors, the less the score of the essay. This can be explained, as commented previously, by the fact, that as defined above, semantic lexical errors refer to the wrong word choice, the use of a L1 word, adapted to the L2 or not, and confusion of similar words. According to this definition, these are the errors that most affect comprehension and intelligibility of the composition, therefore, they are the most severely judged. This is in consonance with Ellis' findings (1994) and with those of Hughes and Lascaratou (1982). Nonetheless, the correlation found is so low, that a clear, conclusive relationship between the type of lexical error and the quality of composition cannot be categorically stated.

No significant correlation was found between the other types of lexical errors and quality of composition. In table 1 the results are presented for the general measure of lexical errors and for the different types for which correlation was calculated.

Table 1 Correlation for the different percentages of lexical error and its types.

\begin{tabular}{|c|c|c|c|c|}
\hline$\%$ lexical errors & $\%$ semantic & $\%$ syntactic & $\%$ orthographic & $\%$ pragmatic \\
-.78 & -.55 & -.52 & -.30 & -.39 \\
\hline
\end{tabular}

$\mathrm{r}(\mathrm{p}<.01)$ 
Another important fact is that semantic errors are also the most numerous, together with orthographic errors. It could be argued, that this could have also influenced on the correlation found, and it is the result of sheer coincidence. However, no significant correlation between orthographic errors and scores was found, this proves that the correlations are not accidental, but that they show real tendencies. Orthographic errors did not score bad, because they are easy to decipher, and, thus, they did not pose any comprehension effort or problem to the judges. The less frequent lexical errors were pragmatic errors, this fact can be explained by remitting to the presentation of the task. Students had to write a letter, therefore, the style, register, and genre conventions are perfectly clear. The correlation found revealed that the lexical errors that affect quality of written compositions the least were orthographic errors. This supports the idea discussed above, that this type of lexical errors, although very frequent, has little impact on the quality of composition as measured by scores, because these lexical errors do not affect intelligibility of the message, since they are easy to identify and to comprehend.

It can be argued that different judges would have accounted for relatively different scores, for example native judges or judges with a mother tongue other than Spanish. I also assume that the number of judges and of compositions is very low in order for this study to be conclusive. Correlations have revealed tendencies, but not truths. This is just a preliminary study, much research on this topic is still needed to reach conclusive assertions.

Taking the results of the significant, although moderate correlation between lexical errors and semantic errors, and quality of composition, predictions could be made as for the score from the percentage of lexical errors and of semantic lexical errors. The relationship is, I consider, meaningful enough to allow us to make predictions of quality of compositions. This has important consequences for planners of writing courses. These findings are also relevant for evaluation, since thanks to the stated relationship, teachers can count on objective evaluation criteria based on the percentage of lexical errors, and of their types. Teaching can also benefit from the results of this study by providing learners with wordlists of problematic lexical items and the lexical errors they are affected by. Practicing exercises will account for a reduction in the number of lexical errors, and thus, for an improvement of the quality of student's written tasks.

\section{Conclusion}

This paper has examined the relationship between lexical errors and quality of composition based on holistic scores. It has confirmed the result already found in Engber (1995) that established, although dimly, the relationship between the mentioned variables. The results here obtained revealed a significant correlation between the absolute frequency of lexical errors and the quality of written essays measured through holistic criteria based on the communicative value of the compositions. This study has gone one step further, and it has also set to prove the relationship between different lexical errors types and again quality of composition. Once more, the result revealed that the initial hypothesis of the correlation between semantic lexical errors and the scores obtained by the compositions was right, and it could be accepted, with certain reservations, though. It is necessary to insist on the idea, 
that correlation coefficients simply show tendencies and not truths, further research is needed on this area and on this topic in order to find more about this relationship and its nature.

Here a definition of lexical error and a classification of lexical errors have been proposed in order to systematize research in this field. However, for the analysis of correlation only one criterion was used, namely the linguistic. The scope of this study prevented us from going further and establishing, or at least, attempting at establishing the relationship between the source of the lexical errors and quality of composition, and between this and the class of word affected by the error. This should be topics for further research. The relationship between topic of composition, lexical errors, and quality of composition is also very interesting and it may provide the researcher with important findings about what are the most problematic areas in second language writing, and thus, help the teacher with information and possible solutions for the second language classroom, as regards teaching a second language and evaluating written tasks in that language.

\section{REFERENCES}

Agustín Llach, M.P. (in press). "Lexical Deficiencies and Inconsistencies in English Second Language Learners: Proposal of Classification", in Interlingüística, 15.

Bahns, J. (1993). "Lexical Collocation. A Contrastive View", in ELT Journal, 47, 1: 56-63.

Blum, S., and Levenston E. A. (1978). "Universals of lexical Simplification", in Language Learning, 28: 399-415.

Briz, A. (2002). El español coloquial en la clase E/LE. Un recorrido a través de los textos. Madrid: SGEL.

Corder, S. P. (1973). Introducing Applied Linguistics. Middlesex: Penguin Books.

Crusan, D. (2002). "An Assessment of ESL Writing Placement Assessment”, in Assessing Writing, 8: $17-30$.

Dagut, M. B. (1977). "Incongruencies in Lexical ÔGridding' - An Application ofContrastive Semantic Analysis to Language Teaching”, in IRAL, 15, 3: 221-29.

Denyer, M. (1998). La lectura: una destreza pragmática y cognitivamente activa. Madrid: Fundación Antonio Nebrija.

Duöková, L. (1969). "On Sources of Errors in Foreign Language Learning”, in IRAL, 7, 1: 1136.

Ellis, R. (1994). The Study of Second Language Acquisition. Oxford: Oxford University Press.

Engber, C. A. (1995). "The Relationship of Lexical Proficiency to the Quality of ESL Compositions", in Journal of Second Language Writing, 4, 2: 139-55.

Gass, S. (1988). "Second Language Vocabulary Acquisition", in Annual Review of Applied Linguistics, 9: 92-106.

Grabe, W., and Stoller, F. (1997). "Reading and Vocabulary Development in a Second Language: A Case Study", en J. Coady and T. Huckin (eds.), Second Language Vocabulary Acquisition. Cambridge: Cambridge University Press, 98-122.

Hughes and Lascaratou (1982). "Competing Criteria for Error Gravity.", in Language Learning, 36: $175-82$. 
Hyltenstam, K. (1988). "Lexical Characteristics of Near-Native Second Language Learners of Swedish", in Journal of Multilingual and Multicultural Development , 9: 67-84.

Jacobs, H.L.et al. (1981). Testing ESL Composition. A Practical Approach. Rowley, Mass. : Newbury House.

Jarvis, S. et al. (2003). "Exploring multiple profiles of highly rated learner compositions", in Journal of Second Language Writing (in press).

Jiménez Catalán, R. M. (1992). Errores en la producción escrita del inglés y posibles factores condicionantes. Madrid: Universidad Complutense.

Johansson, S. (1978)."Problems in Studying the Communicative Effect of Learner's Errors", in SSLA, 1, 1: 41-52.

Laufer, B. (1986). "Possible Changes in Attitude Towards Vocabulary Acquisition Research", in IRAL, 24, 1: 69-75.

- - (1990a). "'Sequence' and ÔOrder' in the Development of L2 Lexis: Some Evidence from Lexical Confusions", in Applied Linguistics, 11, 3: 281-96.

- - (1990b). "Why Are Some Words More Difficult than Others?- Some Intralexical Factors that Affect the Learning of Words", in IRAL, 28, 4: 293-307.

(1991). "Some Properties of the Foreign Language Learner's Lexicon as Evidenced by Lexical Confusions", en IRAL, 29, 4: 317-30.

(1997). "The Lexical Plight in Second Language Reading”, in J. Coady, and T. Huchkin, (eds), Second Language Vocabulary Acquisition. Cambridge: Cambridge University Press, 20-34.

Laufer, B., and Nation, P. (1995). "Vocabulary Size: Lexical Richness in L2 Written Production", in Applied Linguistics, 16: 307-22.

Lennon, P. (1990). "Error: Some Problems of Definition, Identification, and Distinction", in Applied Linguistics, 12, 2: 180-95.

- - (1991). "Error and the very Advanced Learner", in IRAL, 29, 1: 31-44.

Llobera, M. (1995). Competencia Comunicativa. Documentos básicos en la enseñanza de lenguas extranjeras. Madrid: EDELSA.

Maingay, S., and Rundell, M. (1987) “Anticipating Learners' Errors- Implications for Dictionary Writers", in A. Cowie (ed.), The Dictionary and the Language Learner. Tübingen: Max Niemeyer, 128-35.

Meara, P. (1984). "The Study of Lexis in Interlanguage", in A. Davies, C. Criper, and A. P. R. Howatt (eds.), Interlanguage. Edinburgh: Edinburgh University Press, 225-235.

- - (1996). "The Dimensions of Lexical Competence", in . G. Brown, K. Malmkjaer and J Williams (eds.), Performance and Competence in Second Language Acquisition. Cambridge: Cambridge University Press, 35-53.

Meara P. et. al (2000). "Vocabulary and neural networks in the computational assessment of texts written by second language learners", in System, 28: 345-354.

Muncie, J. (2002). "Process Writing and Vocabulary Development: Comparing Lexical Frequency Profiles Across Drafts", in System, 30: 225-235.

Richards, J. (1971). "A Non-Contrastive Approach to Error Analysis", in English Language Teaching, 25: 204-19.

Taylor, B. (1975). "The use of overgeneralization and transfer learning strategies by elementary and intermediate students of ESL", in Language Learning, 25, 1: 73-107.

Verhallen, M., and Schoonen, R. (1993). "Lexical Knowledge of Monolingual and Bilingual Children", in Applied Linguistics, 4: 344-63. 
_- (1998). "Lexical Knowledge in L1 and L2 of Third and Fifth Graders.", in Applied Linguistics, 19: 452-70.

Warren, B. (1982). "Common Types of Lexical Errors among Swedish Learners of English", in Moderna Språk, 76, 3: 209-28.

Widdowson, H.G. (1995). "Conocimiento de la lengua y habilidad para usarla", in Llobera, M. (ed.), Competencia Comunicativa. Documentos básicos en la enseñanza de lenguas extranjeras. Madrid: EDELSA, 83-90.

Yoshida, M. (1978). "The Acquisition of English Vocabulary by a Japanese-speaking Child", in E.M Hatch (ed.), Second Language Acquisition. A book of readings. Rowley, Ma: Newbury House, 91-100.

Zimmermann, R. (1986). "Semantics and Lexical Error Analysis", in Englisch-Amerikanische Studien, 2: 294-305.

- - (1987). "Form-oriented and Content-oriented Lexical Errors in L2 Learners", in IRAL, 25, 1:55-67.

Zughoul, M. R. (1991). "Lexical Choice: Towards Writing Problematic Word Lists", in IRAL, 29, 1: $45-60$. 


\section{APPENDIX A}

\section{Scoring Criteria}

6 The paper is obviously communicative. It effectively addresses the question/topic. It is well organized, with clearly appropriate details that support a thesis and illustrate ideas. Language use is consistently fluent, although there may be occasional errors. Word choice is appropriate and varied. Usage is idiomatic. Complex and varied syntax is evident. There are few errors in agreement, tense, prepositions, pronouns, or other grammatical structures. Indicates mastery of the conventions of English.

5 The paper is communicative. It addresses the question/topic but does so less effectively than a paper that scores a 6. It is generally well organized with details that support a thesis and illustrate ideas. Language use is fluent but may be somewhat inconsistent. Some variety in word choice is evident. Usage is usually idiomatic. The writer shows some evidence of facility with complex and varied syntax. Occasional errors in agreement, tense, and other grammatical structures will probably occur. Indicates generally correct use of the conventions of English.

4 The paper communicates adequately. It addresses the question/topic, but development is limited. It is adequately organized, with a clear plan and some details to support a thesis. Language use is inconsistent but does not obscure meaning. Word choice is generally appropriate but may not be varied. The writer shows familiarity with complex constructions and consistency in the use of simple, correct syntax. Several errors in agreement, tense, and other grammatical structures will probably occur. Occasional errors in the conventions of English occur.

3 The paper is communicatively limited. It addresses the question/topic but has several weaknesses. Organization may be uneven. Support may be insufficient or inappropriate. Language use may at times obscure meaning. Inappropriate word choice and repetition are characteristic. The paper exhibits accumulation of errors in simple syntactic constructions and other grammatical structures. Errors in the conventions of English may occur.

2 The paper is minimally communicative. It may not address the question/topic or do so only superficially. It is seriously disorganized, with no clear plan. Few appropriate details are used; irrelevant material may be introduced. Language use, including word choice, may seriously obscure meaning. There are frequent errors in syntax and other grammatical structures. Errors in the conventions of English are usually evident.

1 The paper may not communicate. Severe and frequent errors in all areas- organization, development, language use, vocabulary, syntax, and English conventions- are characteristic.

The scoring criteria are taken form Engber (1995: 153-154) who herself adapted them from the Test of Written English (TWE) Scoring Guide by permission of the Educational Testing Service, the copyright owner. 


\section{APPENDIX B}

\begin{tabular}{|c|c|c|c|c|c|c|}
\hline $\begin{array}{c}\text { Compositio } \\
\mathrm{n}\end{array}$ & $\begin{array}{c}\text { Mean } \\
\text { score }\end{array}$ & $\begin{array}{c}\text { \% of } \\
\text { lexical } \\
\text { error }\end{array}$ & $\begin{array}{c}\text { \% of } \\
\text { semantic } \\
\text { lexical } \\
\text { error }\end{array}$ & $\begin{array}{c}\text { \% of } \\
\text { syntactic } \\
\text { lexical } \\
\text { error }\end{array}$ & $\begin{array}{c}\text { \% of } \\
\text { orthographic } \\
\text { lexical } \\
\text { error }\end{array}$ & $\begin{array}{c}\text { \% of } \\
\text { pragmatic } \\
\text { lexical } \\
\text { error }\end{array}$ \\
\hline 1 & 3,5 & 11,25 & 5,41 & 1,25 & 3,33 & 1,25 \\
\hline 2 & 4,5 & 3,96 & 2,74 & 0,30 & 0,60 & 0,30 \\
\hline 3 & 2,5 & 9,69 & 2,64 & 1,76 & 4,84 & 0,44 \\
\hline 4 & 1 & 12,96 & 6,48 & 0,92 & 4,62 & 0 \\
\hline 5 & 3 & 10,61 & 3,11 & 3,55 & 3,11 & 0,88 \\
\hline 6 & 1,5 & 13,99 & 6,58 & 5,34 & 0,41 & 0,82 \\
\hline 7 & 1 & 15,62 & 6,08 & 4,34 & 3,47 & 1,73 \\
\hline 8 & 1 & 10,76 & 3,84 & 3,07 & 3,84 & 0 \\
\hline 9 & 3 & 7,11 & 3,13 & 1,96 & 0,78 & 0,39 \\
\hline 10 & 3,5 & 6,25 & 2,23 & 1,78 & 1,78 & 0,44 \\
\hline 11 & 2 & 10,48 & 3,22 & 3,22 & 0,80 & 3,22 \\
\hline 12 & 2 & 9,47 & 4,21 & 2,63 & 1,57 & 1,05 \\
\hline 13 & 2,5 & 11,11 & 3,70 & 1,23 & 5,55 & 0,61 \\
\hline 14 & 3 & 7,96 & 3,58 & 1,99 & 2,39 & 0 \\
\hline 15 & 3,5 & 7,69 & 3,41 & 1,28 & 2,13 & 0,85 \\
\hline 16 & 2,5 & 9,80 & 4,41 & 2,45 & 2,94 & 0 \\
\hline 17 & 2 & 11,18 & 2,63 & 1,97 & 4,60 & 1,97 \\
\hline 18 & 2 & 11,33 & 6 & 2 & 0,66 & 2,66 \\
\hline 19 & 2 & 10,52 & 4,21 & 1,57 & 3,15 & 1,57 \\
\hline
\end{tabular}

